\title{
DOE Backup Power Working Group Best Practices Handbook for Maintenance and Operation of Engine Generators, Volume II
}

by

R. E. Gross

Westinghouse Savannah River Company

Savannah River Site

Aiken, South Carolina 29808

K. P. Burrows

A. Padgett

J. Laukea

M. Wong

\section{DOE Contract No. DE-AC09-96SR18500}

This paper was prepared in connection with work done under the above contract number with the U.S. Department of Energy. By acceptance of this paper, the publisher and/or recipient acknowledges the U. S. Government's right to retain a nonexclusive, royalty-free license in and to any copyright covering this paper, along with the right to reproduce and to authorize others to reproduce all or part of the copyrighted paper. 


\section{DISCLAIMER}

This report was prepared as an account of work sponsored by an agency of the United States Government. Neither the United States Government nor any agency thereof, nor any of their employees, makes any warranty, express or implied, or assumes any legal liability or responsibility for the accuracy, completeness, or usefulness of any information, apparatus, product, or process disclosed, or represents that its use would not infringe privately owned rights. Reference herein to any specific commercial product, process, or service by trade name, trademark, manufacturer, or otherwise does not necessarily constitute or imply its endorsement, recommendation, or favoring by the United States Government or any agency thereof. The views and opinions of authors expressed herein do.not necessarily state or reflect those of the United States Government or any agency thereof.

This report has been reproduced directly from the best available copy.

Available to DOE and DOE contractors from the Office of Scientific and Technical Information, P. O. Box 62, Oak Ridge, TN 37831; prices available from (423) 576-8401.

Available to the public from the National Technical Information Service, U. S. Department of Commerce, 5285. Port Royal Road, Springfield, VA 22161. 


\section{DISCLAIMER}

Portions of this document may be illegible in electronic image products. Images are produced from the best available original document. 
WSRC-TR-98-00330

Revision 0

\section{DOE BACKUP POWER WORKING GROUP}

\section{BEST PRACTICES HANDBOOK FOR MAINTENANCE AND OPERATION OF ENGINE GENERATORS, VOLUME II (U)}

Westinghouse Savannah River Company

Savannah River Site

Aiken, SC 29808

Prepared for the U.S. Department of Energy under Contract No. DE-AC09-96SR18500 
WSRC-TR-98-00330

Revision 0

\section{DOE BACKUP POWER WORKING GROUP}

\section{BEST PRACTICES HANDBOOK FOR MAINTENANCE AND OPERATION OF ENGINE GENERATORS, VOLUME II (U)}

Westinghouse Savannah River Company

Savannah River Site

Aiken, SC 29808

Prepared for the U.S. Department of Energy under Contract No. DE-AC09-96SR18500 
WSRC-TR-98-00330

Revision 0

\section{FORWARD}

Chapters in this handbook are intended to supplement original equipment manufacturer (OEM) information and practices primarily for stationary gasoline and diesel engines. The guidelines presented in the following chapters are based on available literature and the experience of the Engine Generator Subcommittee members. Hopefully, this and subsequent volumes will promote consistent best practices throughout the DOE complex in meeting the requirements contained in DOE-STD-3003-94, DOE Standard Backup Power Sources for DOE Facilities.

This document is suitable for voluntary use by engineers and technicians responsible for Backup Power Sources at DOE facilities.

Beneficial comments, including additions, deletions or corrections are encouraged and may be forwarded to the BPWG through Mr. John Fredlund, DP-45 GTN, U.S.

Department of Energy, Germantown, MD 20874-1290; (301) 903-3059, FAX (301) 9038754.

This document is unclassified. 
WSRC-TR-98-00330

Revision 0

\section{ACKNOWLEDGMENTS}

From 1996 to the present date, the Engine Generator Subcommittee of the Backup Power Working Group has drafted, edited and compiled the chapter(s) contained in this volume. Members represent Maintenance, Operation and Engineering disciplines from most U.S. Department of Energy (DOE) sites.

Members who participated in draft, review and edit sessions include:

Gary Borba, DOE-SR

John Goodrich, LANL

Al Martinez, LANL

Bob Henderson, INEL

Howard Mason, RFETS

Jack Goldenberg, SRS

Alvin Padgett, SRS

Ken Burrows, SRS

Ken Hoopingarner, PNL

Karl Frazier, DOE-SR

Jug Uppal, ANL-E

Jim Ross, SAIC

Larry L. Davis, LMITCO

John laukea, SRS

Ken Freiberg, EASI

Keith Martin, RFETS

Roger Barklund, LMITCO

Bill Clapp, INEL

Jorge Alva, WIPP

Ming Wong, SRS

Jeff Baver, Mound

Phil Hartung, DOE-RF

John Fredlund, DP-45

Robert Gross, SRS / chairman 
VOLUME II

TABLE OF CONTENTS

\section{CHAPTER ONE}

Guidelines and Best Practices for the Design and Maintenance of Engine Lube Oil Systems

I. INTRODUCTION 1

II. DESIGN 2

1. Lube Oils . 2

2. Pumps

A. Engine Mounted 2

B. Standby and Prelube 3

C. Recirculating 4

3. Sumps

4. Oil Coolers

5. Lube Oil Temperature Regulating Valves

6. Filters / Strainers 5

7. Alarms and Shutdowns

A. Low Oil Pressure Alarm 5

B. Low-Low Oil Pressure Shutdown 6

C. High Oil Temperature Alarm 6

D. High Oil Temperature Shutdown 6

E. High Differential Oil Pressure Alarm 6

F. Low Oil Temperature 6

G. Low Circulating Oil Pressure 6

$\mathrm{H}$. Low Turbocharger Circulating Oil Pressure 6

8. Oil Heaters

A. Operating Lube Oil Pre-Heaters 7

$\begin{array}{ll}\text { B. Sizing and Settings } & 7\end{array}$

III. $\quad$ LUBE OIL ANALYSIS 8

1. History of Oil Analysis 8

2. Analysis Methods

A. Spectrochemical analysis $\quad 8$

B. Physical Analysis 8

C. Particle Counting 8

D. Direct Reading Ferrography 8

E. Analytical Ferrography 9

3. Uses for Analysis

A. Receipt Sampling 9

B. Extending Oil Changes 9

C. Condition Based Overhauls 9

D. Improper Lubricants $\quad 10$ 
4. Analysis Criteria

5. Sampling Frequency Guidelines

6. Sampling - When, Where and How

A. When to Sample

B. Sample Points

C. Taking a Sample

7. The Sample Process

8. A Basic Oil Analysis Program

9. Estimated Cost of Oil analysis

IV. TYPES OF OILS

1. Petroleum Oil vs. Synthetic Oil

15

2. Multi-viscosity Oil

15

3. Zinc-Free Oil

4. Engine Oil Additives

V. RECOMMENDED OIL GRADES 17

$\begin{array}{lll}\text { VI. DISPOSITION OF USED OILS } & 18\end{array}$

$\begin{array}{ll}\text { VII. FLUSHING OIL SYSTEMS } & 19\end{array}$

$\begin{array}{ll}\text { VIII. PRESERVATIVE OILS } & 20\end{array}$

$\begin{array}{ll}\text { IX. } & \text { REFERENCES }\end{array}$ 


\section{CHAPTER 1}

\section{Lubricating Oil Systems}

\section{INTRODUCTION}

The lubricating oil system provides a means to introduce a lubricant in the form of a film to reduce friction and wear between surfaces that bear against each other as they move. 1 The oil film which is established also cools the parts by carrying generated heat away from hot surfaces, cleans and carries dirt or metal wear particles to the filter media, and helps seal the piston to the cylinder during combustion. Most systems are pressure lubricated and distribute oil under pressure to bearings, gears, and power assemblies. Lubricating oil usually reaches main, connecting rod, and camshaft bearings through drilled passages in the cylinder block and crankshaft or through piping and common manifolds.

Many parts rely on oil for cooling, so if the lube oil system fails to perform its function the engine will overheat. Metal to metal surfaces not separated by a thin film of oil rapidly build up frictional heat. As the metals reach their melting point, they tend to weld together in spots or streaks. Lube oil system failures can cause significant damage to an engine in a short period of time. Proper maintenance and operation of the lubricating oil system is essential if your engine is to accomplish its mission. 


\section{DESIGN}

The lube oil system of a modern diesel or gas engine includes the lubricating oil itself, oil sump (either on or off engine), oil pumps, internal passages through the block, external piping, valves, filters and filter banks, strainers, coolers, pressure regulators, instruments, alarms and shutdown devices.

\section{Lubricating Oils}

Three general types of lube oils are used today. Straight mineral oils which are produced entirely from natural "petroleum" base, synthetic oils which are derived from hydrocarbons, esters, glycols or silicones and finally "additive" oils which are petroleum oils having enhanced properties. Those properties include slower oxidation, better corrosion inhibition, increased film strength, greater solid particle suspension, high viscosity, lower pour point and increased friction and wear properties. ${ }^{2}$ Straight mineral oils should not be used as lubricants, with some rare exceptions, due to their poor lubricating properties and very short service life.

Viscosity is probably the most important lube oil property. It is a measure of resistance to flow, A thick oil has high viscosity while a thin oil has low viscosity. Generally, the higher viscosity oil has better ability to maintain the fluid film between wearing surfaces even when pressed together with great force. Viscosity is greatly affected by temperature in that the viscosity drops drastically as the temperature increases. Viscosity Index (VI) is a measure of how viscosity changes with temperature. Viscosity improvers are used to keep the rate of change of viscosity to a minimum from low to high temperature. Synthetic oils and multi-viscosity oils which contain $\mathrm{VI}$ additives are discussed in more detail later in this chapter.

\section{Pumps}

\section{A. Engine Mounted}

Lubricating oil pumps for engines are positive-displacement type and may be driven by the engine itself or by an electric motor. Changes in engine speed cause corresponding changes in pump output. Pumps usually provide 30-70 psig or even more header pressure, depending on the particular engine design. Enough flow capacity is provided by lube oil pumps for full load and idle conditions, and sufficient to provide adequate flow and pressure when bearing clearances increase. The positive displacement pump will always have a relief valve or relief mechanism to prevent damage from high pressures as when cold oil is pumped during start/warm-up period.

Flow rate through the engine is usually selected so that the rise in oil temperature across the engine, that is between oil entering the engine and that leaving is approximately $25^{\circ}-40^{\circ} \mathrm{F}$. Many engines today can operate with an oil outlet temperature as high as $250^{\circ} \mathrm{F}$ under rated load but oil usually kept near the same temperature as the jacket water outlet. It is desirable to maintain top oil and water temperatures the same to minimize thermal distortion. The lower the oil temperature, the greater the oil film thickness will be. ${ }^{3}$

\section{B. Standby and Pre-lube}

Standby and pre-lube pumps are available for both large and small engines. Standby pumps, also called auxiliary pumps, may be used as added insurance if the engine pump capability is lost for some reason. A standby pump taking suction on the engine sump will continue to provide oil pressure to the engine. Larger, more costly, or critical applications should consider installing the standby pump for reliability. Pre-lubricating pumps can be hand operated, or electric motor operated. They are used to pump sump oil into the main gallery, main bearings, connecting rod 
bearings and other critical points to reduce the amount of metal to metal contact and wear during startup.

There is controversy over how often and how long to pre-lubricate engines. Interviews with vendors and current vendor literature support from once a week or before each start to once per month. The amount of time to pre-lubricate depends on how long it takes for oil to reach the valve train of the cylinder head. Five minutes on most engines is typical. If the pre-lube period is too long oil will run down valve guides and accumulate in the combustion chamber. If this occurs, the cylinder may become hydraulically locked as the piston comes to top dead center. Trapped fluid will prevent the engine from turning and may cause a connecting rod to bend. Pre-lube time should be sufficient to only wet the wearing surfaces before the engine is started. The engine should be primed only until the engine lubricating oil pressure gage registers a slight pressure or until oil is seen at each main bearing and the valve train. ${ }^{4}$ It is best to determine the optimum time for each engine through actual field experience. Vendors may give rules of thumb, but field data and direct observation are essential.

With modern high technology oils, the concern for drying of oil films during periods of standby are not what they once were. Qualitative field testing at one site has indicated that when cylinder liners were maintained in the range $100-150^{\circ} \mathrm{F}$, more than 60 days was required for the oil film to dissipate. ${ }^{5}$ Naturally, over that period of time, the film gets thinner but sufficient lubrication is available to reduce or eliminate liner scuffing which is a prelude to scoring and permanent cylinder damage during startup. Consequently, even pre-heated engines may be started and operated on a 30 day surveillance schedule without damage to cylinders during startup. This assumes the engine is not rapidly loaded. Pre-lubrication is typically used on larger engines whenever they are test started and on smaller engines that are being started after having been out of service for extended periods. 


\section{Recirculating Pumps}

Some recirculating pumps are in continuous operation during shutdown periods. This is especially true for larger engines and on those engines in a critical start application where the requirement to be started and loaded may be less than 10 seconds. The recirculating oil system keeps the main bearing line lubricated with heated oil. This method has been particularly useful on diesels with aluminum bearings and turbochargers. A more detailed description of the General Motors Electro-Motive Division (EMD) system is explained below.

The EMD system with turbocharger consists of a jacket water immersion heater and two positive displacement pumps. One pump is for lubricating the main and connecting rod bearings and the other for lubricating the turbocharger bearing. The immersion heater heats the jacket water and then circulates it through the oil cooler by thermo-siphon. As the coolant passes through the oil cooler, it heats the lube oil making it easier to pump. The main circulating pump maintains oil in the external oil system accessories (filter housings, piping, etc.) to prevent oil starvation upon start-up. The immersion heater is de-energized while the engine is running to prevent damage to the heater elements.

A dedicated supply of oil to the turbocharger is required due to the vulnerability of the turbocharger bearing to operate with a limited oil supply. Without the turbocharger lubricating pump, the turbocharger bearing could be damaged due to lack of lube oil upon start-up. Also, the high temperature environment in which the turbocharger operates can cause bearing damage if oil is not supplied to the bearing immediately after shutdown of the engine. The turbocharger continues to spin for up to a minute after the engine is secured, so a dedicated turbocharger lube oil pump is provided.

\section{Sumps}

After oil in an engine has done its lubricating and cooling job, it drops back to an integral or external tank commonly known as a wet or dry sump. The wet sump is integral. A dry sump design incorporates a separate oil tank located near to, but not part of, the engine itself. Typically a pressure pump and scavenger pump are required for dry sumps. Pipe connections to dry sumps should enter at or near the top of the tank to minimize spill and fire hazards should a pipe break. Sumps should be large enough to hold the initial charge of oil for the engine, plus an amount needed to makeup for that consumed during engine operation. High and low level indicator, alarms, and temperature gages should be installed.

\section{Oil Coolers}

Oil can suffer irreversible damage at extreme temperatures hence the need for heat exchangers. Heat exchangers are used on modern engines to cool below a temperature that would permanently damage the lubricating oil. That temperature is generally recognized as $250^{\circ} \mathrm{F}$. Prolonged, sustained oil temperature in this range can break the oil down by oxidation and cause carbon to plate out on sensitive machine surfaces. The lube oil cooler is used to maintain vendor recommended oil temperatures. Generally, the jacket water is used to cool lube oil, but in some larger engines, domestic water or salt water may be used to carry the heat energy away from the engine.

Oil that is too cold can cause problems. The engine works harder to push cold oil through internal oil passages increasing fuel consumption. Just the right temperature and viscosity of oil is needed to reach into tight bearing clearances and lubricate mating surfaces. Temperature regulating valves are used on larger engines to maintain proper lube oil temperature. In smaller engines, lube oil temperature is essentially a function of the jacket water temperature regulated by the water thermostat. Consequently, lubricating oil temperature will follow and be greater than the 
engine jacket water temperature once stabilized at load. The most common lube oil cooler is the shell and tube type. Oil is usually passed through the shell side of the cooler.

\section{Lube Oil Temperature Regulating Valves}

On some large diesels, regulating valves are used to control the lube oil temperature. The regulating valve is basically a three way thermostatic valve. It diverts an increasing amount of oil to the lube oil cooler resulting in a decrease in the bulk oil temperature. As the oil temperature decreases the amount of oil flowing to the oil cooler diminishes.

\section{Filters / Strainers}

Paper cartridge type filters or elements are used today in most low and medium speed engines to remove contaminants from the oil. They are usually mounted prior to the cooler so filtering is done while the oil is hot. Full flow strainers and filters are the general rule, but some older applications may be bypass type systems. In the by pass system, a side stream of oil is sent from the oil sump through strainer and filter and returned to the sump. Full flow filters ensure that all oil being sent to the engine for lubrication and cooling has been filtered. Filtering may be done using 25 micron ( 0.001 inch) filter media. This filter is capable of removing particles in the oil as small as 25 microns, but some filters are designed to remove down to 10-15 micron size particles. Filter efficiency is measured by the beta ratio (used to be nominal rating system) and is the ratio of inlet particles versus the number of same size particles in the outlet stream.

Strainers can be single or duplex and are usually mounted on the suction side of pumps to protect pump internals from larger particles. They may be fitted with magnets to remove metal particles. Duplex filters / strainers are designed to be shifted from one bank or filter to another while the other is being changed or cleaned.

When possible, filter housings should be mounted such that the filters do not drain back to the sump after the engine is shutdown. This can be accomplished by the orientation of the filters and or a check valve. The primary concerns are lack of lubrication to vital engine parts during startup, and varying sump levels. Shortly after an engine run the sump may be considered too low, and therefore addition of oil at this time may cause an overfull condition when the oil from the filter drains back to the sump. Filter cartridges with no metal content are recommended because they can be easier to discard. More information on filter construction, media, centrifuges and purifiers is available. ${ }^{6}$

\section{Alarms and Shutdowns}

The application of alarms and shutdowns on diesel lube oil systems varies between installation and application. The following presents some available options, and is not meant to be complete list. In some applications the shutdowns are only active when in the manual or test mode. An automatic start may cause the shutdowns to be bypassed allowing the engine to run even in the alarm condition.

\section{A. Low Oil Pressure Alarm}

This alarm will actuate when oil pressure drops to a level below the normal operating range, but not low enough to cause engine damage. The purpose of the low oil pressure alarm is to alert the operator of the condition and to allow time to take action that would prevent further decrease in pressure. This alarm could be an indication of a pump failure either the pressure or scavenging pump, lack of oil supply due to low oil level, or blocked suction strainers. 


\section{B. Low-Low Oil Pressure Shutdown}

This shutdown feature will actuate when oil pressure drops to a level at which engine damage is imminent.

\section{c. High Oil Temperature Alarm}

This alarm will actuate when oil temperature is approaching a level above the normal range, but not high enough to cause engine damage. The purpose is to alert the operator of the condition so action may be taken to prevent a further increase in oil temperature, or to reduce damage caused by a further increase in oil temperature. This alarm could be an indication of lube oil heat exchanger fouling, low oil level, or oil pump failure.

\section{Hi-Hi Oil Temperature Shutdown}

This shutdown feature will actuate when oil temperature rises to a level at which engine damage is imminent.

\section{E. High Differential Oil Pressure Alarm}

This alarm will actuate when the differential pressure across the lube oil filters approaches a value which could damage the filters, or starve the engine lube oil pump, causing cavitation. The alarm indicates a blockage in the filter. Many filter housings or filters themselves have relief devices that bypass the filters when the differential pressure becomes too high. This will prevent the damage to the filter and pump, however when bypassing occurs, the oil is no longer being filtered.

\section{F. Low Oil Temperature}

This alarm will normally be provided when the diesel generator is equipped with a lube oil heating system for standby operations. The alarm will indicate that the circulation/heating system is malfunctioning, which could affect the engine start time.

\section{G. Low Circulating Oil Pressure}

This alarm will be provided for diesel generator systems equipped with an auxiliary lube oil circulating pump for pre-lubrication. The alarm indicates a failure of the circulating pump system or a blockage in the lube oil circulation lines or filters as indicated by low downstream pressure. This alarm may tie in to an interlock circuit. The interlock will prevent engine starting if the lube oil pressure is not restored within a certain time period.

\section{H. Low Turbocharger Circulating Oil Pressure}

This alarm will be provided for diesel generator systems equipped with an auxiliary lube oil circulating pump for pre-lubrication of the turbocharger bearing. The alarm could indicate a failure of the circulating pump system or a blockage in the turbocharger lube oil circulation lines or filter. This alarm may tie to an interlock circuit. The interlock will start the auxiliary turbocharger lubricating pump (if provided) and will prevent the engine starting if the lube oil pressure is not restored within a certain time period.

\section{Oil Heaters}

Based on the local ambient temperatures, oil heaters are sometimes recommended to eliminate cold and dry starts. Cold oil is very viscous and resists flow. After extended periods between engine runs, the oil film between critical engine parts may have dissipated. When the engine is 
started in this condition considerable force is required to fill the critical clearances with oil fast enough to prevent metal to metal contact in the highly loaded areas of the engine. Preheating the oil to the desired temperature reduces its resistance to flow and therefore reduces the time required to fill the critical engine clearances. This reduces frictional drag and metal-to-metal wear on start-up.

\section{A. Operating Lube Oil Pre-Heaters}

Lube oil preheating systems are similar to engine coolant preheaters in that they consist of an element, thermostat and AC power source. The element is inserted in the oil pan or reservoir and a thermostat is mounted slightly above and to one side of the element to control the temperature. To prevent overheating the oil, the oil heater can be interlocked to de-energize when the diesel starts. However, this is not necessary as the thermostat has a fairly quick response time and deenergizes the element shortly after start-up of the diesel. The heater element and thermostat should be located well below the "low" oil level mark on the dipstick. This prevents damaging the element and properly regulates the bulk temperature of the oil. ${ }^{7}$

\section{B. Sizing and Settings}

Lube oil heaters are available in numerous voltage settings. For single phase power one might choose from $120,208,240,277,380,415,440$ and 480 , for three phase power there is 208,240 , $380,415,440,480,575$ and 600 volts. General purpose, watertight, and explosion resistant enclosures and switches are available. Various temperature settings are available, but typical ranges are from 40 deg. $F$ to 160 deg. $F$ in 20 deg. spans. The lower number specified on the thermostat is the setpoint at which the element is energized, and the higher number is the setpoint at which it is de-energized. Sufficient lubrication upon start-up will be provided if the oil's bulk temperature is about $100 \mathrm{deg}$. F. Little benefit is gained by heating the oil above this temperature. To minimize operating cost and increase element life a thermostat setting of $80-120 \mathrm{deg}$. $F$ is recommended.

Sizing of oil heater elements is based on the sump capacity. A good rule of thumb for mild ambient conditions (minimum winter temperatures of approximately 0 deg. F) is 20-25 watts per gallon. For more severe, arctic conditions, 45 watts per gallon is recommended. To extend element life and prevent burning the oil, element loading should not exceed 20 watts per square inch of element surface area. Once this loading is exceeded, more elements or a larger one should be used to handle the same capacity. Some sheathed elements are provided to assist with this problem.

Lube oil heaters improve engine lubrication upon start-up, therefore reducing wear at the most critical time in the life of a bearing. Since lube oil heaters do not typically heat the combustion area of the block, their use alone may not improve cold start reliability. When it is desired to have a quick, reliable, cold start, coolant preheaters should be used as they continually warm the block and combustion area. 


\section{LUBE OIL ANALYSIS}

There are two purposes for analysis: one, to assess the physical properties of the oil and two, to assess machinery condition. Diesel engine lube oil analysis is the confirmation of engine wear and lubricant breakdown by the detection of increases in the corresponding wear metal content and decreases in the lubricating properties of the oil. It is a predictive maintenance (PdM) tool to be used in conjunction with other PdM tools such as vibration analysis, inspections, root cause analysis of failures and a suitable preventive maintenance program. This paper will focus on its use in a diesel maintenance program.

\section{History}

Oil analysis began in the early 1940's by the railroad industry, as locomotives transitioned from steam to diesel power. The Denver, Rio Grande and Western Railway initiated a program whereby they analyzed the oil of their engines using a spectrograph to detect and measure chemical elements within the oil. The program was successful at identifying the causes of many of their oil related engine failures, and therefore became widely accepted in the rail industry. By 1955 the Navy began experiments with oil analysis on aircraft engines. Their success led the other branches of the military to eventually adopt programs of their own. Since the 1960's many commercial industrial operators of equipment have utilized oil analysis as a predictive maintenance tool.

\section{Methods}

\section{A. Spectrochemical Analysis}

Spectrochemical analysis is the detection and measurement of wear metals (i.e. copper, lead, aluminum, etc.) contaminants (silicon) and additives (calcium, phosphorous, zinc, etc.) in the lube oil reported and trended in parts per million (ppm) by weight.

\section{B. Physical Analysis}

Physical analysis of the oil measures the physical characteristics of the oil such as viscosity, total acid number (TAN) or total base number (TBN). The analysis can detect contamination of the oil by ethylene glycol, water, fuel, oxidation and combustion products.

\section{Particle Counting}

Particle counting is the counting of a specific size range of particles in a specific volume of oil. The particle count can then be compared to International Organization for Standardization (ISO) standards for classification of the cleanliness/contamination of the oil. This method is discouraged when analyzing diesel engine oils, because the detergent oils used in diesels tends to turn dark in color fairly quickly in service. The particle counter uses white light to pass through the fluid to illuminate and discern the size of the particle. For the counter to "see through" the oil it must be diluted several times. Dilution increases the margin of error of the test. This method is however the preferred method for analyzing hydraulic oils which maintain their clarity in service.

\section{Direct Reading Ferrography}

Direct Reading (DR) Ferrography is a method of sorting ferrous wear particles magnetically into two size ranges (small and large) then measuring the density in each range. This is a fairly inexpensive test that can be performed each time a spectrochemical and physical test is performed. A baseline is established and trended. When particle counts increase dramatically, 
Analytical Ferrography should be requested. Direct Reading Ferrography is a screening tool for the more expensive Analytical Ferrography.

\section{E. Analytical Ferrography}

Analytical Ferrography is the visual examination of the wear particles captured on a ferrogram. A ferrogram is nothing more than a highly magnified collage of the wear particles aligned magnetically. Based on the particle size, shape, color, quantity, and composition it can be determined what type of wear metal is being viewed, and the type of wear occurring (abrasive, adhesive, rolling contact, etc.). From this identification, one specific engine component or a list of components can be identified as providing that wear material, and the engine health can be better estimated. This tool should only be used after Direct Reading Ferrography has detected a potential problem could exist. The cost of this test is relatively high. Special test equipment is required to perform the test. Trained and experienced technicians are required to evaluate the ferrogram. It should be noted that analytical ferrography is a another PdM tool that would be used in conjunction with engine operating history, maintenance history, trending and other preventive and predictive tools to make maintenance recommendations. Analytical ferrography should not be used as the sole indicator of engine health or justification for engine teardown.

\section{Uses for Analysis}

\section{A. Receipt Testing}

Receipt testing of new oils upon delivery or prior to use is a good practice when the oils are to be used in critical systems. Contamination of new oils with water or dirt is not uncommon due to packaging deficiencies. Containers can breathe due to changes in temperature of the fluid inside if storage drum bunghole plugs are not sealed tight. When the drums breathe, dirt and water can be ingested into the container. Besides checking for water and contamination, it is important to verify the oil grade and additive package is compatible with the service environment. Physical tests such as ASTM D1744 for water, ASTM D445, D4624 or D4683 for viscosity, and visual (clear and bright / no visible particulate) as a minimum should be used to accept new engine lubricating fluids. Viscosity index is another property that can help identify delivery of the wrong lubricant.

\section{B. Extending Oil Changes}

Oil analysis can be used to extend oil change intervals when the properties of the oil permit it. Many times lubricating oils are changed in equipment based on time-in-use only. This is expensive and does not provide any useful information as to the health of the equipment or the lubricating oil itself. Lube oil analysis can be used to accurately determine oil condition and to extend replacement until the oil begins to degrade. Extending oil changes provides meaningful wear particle analysis and lessons the amount of waste generated. Repeatedly changing the oil potentially masks an engine wear problem because the accumulation of wear metal build-up is lost each time the oil is changed.

\section{Condition Based Overhauls}

Review of wear particle analysis results can be used to help determine if preventive maintenance and overhaul schedules are too rigid or frequent. Replacing components that are still functioning as designed and show no signs of abnormal or excessive wear is not cost effective. Replacement of components based on time rather than condition also increases the risk of failure due to improper installation or installation of marginal components. One company estimates that about $1 / 3$ of maintenance is performed to correct maintenance-induced problems. 


\section{Improper Lubricants}

Qualification of a lubricant can only be measured by actual performance. Mixing different oils is not recommended because the combination of base stocks and additive packages may not have been field tested. The reaction may be unpredictable. Improper lubricant additions and mixing can be detected through the use of analysis. Changes in the additive concentration levels, viscosity, viscosity index, and other physical criteria will quickly indicate if/when a change in the lubricant make-up has occurred.

\section{Analysis Criteria}

Spectrochemical criteria and use limits are very dependent upon the equipment manufacturer, model number, and the lubricant being used. The materials/alloys used in the diesel's internal components varies from manufacturer to manufacturer and from model to model. Therefore, acceptable, marginal, high, and abnormal metal concentration levels need to be established for each engine by trending before the spectrochemical analysis results are meaningful. The amount of engine run-time is very important and must be logged carefully. A large increase in particulate over a long period of time may be completely acceptable, however the same increase may be abnormal if it occurs within a short operating period. The following table illustrates the differences in limits established for some engine manufacturers. The following are warning limits provided by Detroit Diesel Corporation and GM/EMD; an immediate oil change is typically recommended if any of the criteria listed below are exceeded unless stated otherwise.

\section{Detroit Diesel \\ 149 Series}

General Motors EMD Model 645

\section{Viscosity}

(\% Max. Increase)

(\% Max Decrease)

40.0

15.0
30

15

\section{Water}

(\% Max. by Volume)

0.30

No free water allowed

\section{Fuel Dilution}

(\% Max. by Volume)

2.5

5

\begin{tabular}{lcc}
\hline $\begin{array}{l}\text { Pentane Insolubles } \\
(\% \text { Max.) }\end{array}$ & 1.0 & 2.0 \\
\hline $\begin{array}{l}\text { Total Base Number } \\
\text { (TBN Min.) }\end{array}$ & 2.0 & 1.0 \\
\hline $\begin{array}{l}\text { Iron, Fe } \\
\text { (ppm Max.) }\end{array}$ & 35 & $\begin{array}{c}125 \\
\text { Check for rapid wear of } \\
\text { Piston rings and liners }\end{array}$ \\
\hline $\begin{array}{l}\text { Copper, Cu } \\
\text { (ppm Max.) }\end{array}$ & $\begin{array}{c}25 \\
\text { above baseline }\end{array}$ & 150 \\
\hline
\end{tabular}

References 8,9 
Additional resources are available to provide criteria for oil analysis including the equipment manufacturer, the analysis lab, and the Joint Oil Analysis Program (JOAP). 10 The equipment manufacturer typically provides recommendations for oil changes based on time, on the amount of fuel consumed, or on oil analysis results. Minimum values for physical properties, such as TBN, viscosity, contaminant content (EG, fuel, water) fuel soot and total solids build-up are trended. See the vendor literature listed below for more specific criteria. To the equipment manufacturer, once these levels are reached, the oil no longer provides adequate lubricating properties, and engine wear potentially increases to unacceptable levels. Several engine manufacturers provide their own lube oil analysis service. Wear particle, spectrochemical and physical test results are typically compared with the established OEM norms and maximum limits before recommendations are provided.

Many oil analysis labs have developed machinery databases involving thousands of pieces of equipment. Their wear criteria is continually being revised as more data and feedback on a particular models of engines is gathered. Besides physical test criteria, wear particle analysis criteria is available. Although criteria is available, it is stressed that the owner review each analysis report as a whole before any lab recommendations are accepted. It is very important to evaluate the results of all the tests performed. How they compare to each other and the previous results is the most significant information. Trends provide meaningful information than a single data point. Once a reputable, reliable analysis lab has been chosen, it is not recommended to change labs. Results are generally not comparable from lab to lab so valuable trends may become obscured or lost.

The Joint Oil Analysis Program (JOAP) Manual is a comprehensive listing of oil analysis techniques, wear particle analysis limits, severity levels, and recommendations for much of the equipment used in the United States Armed Forces. The criteria is expected to be used in the field as a consistent, systematic approach to oil analysis. This manual is a Department of Defense (DOD) document and authorized to be distributed to U.S. Government agencies and their subcontractors. More information on oil analysis may be obtained from References $8-12$.

\section{Sampling Frequency Guidelines}

Sampling frequency will depend on oil analysis program objectives and might include extension of the oil change interval and evaluation of component wear. A typical sampling guideline for an intermittent use diesel is quarterly to semi-annually. For those diesels that run more frequently and for longer periods, every $250-500$ hours or at the oil change interval whichever occurs first. If an oil change is being based on oil analysis then more frequent sampling, every 125-250 hours, is recommended. ${ }^{13}$ The most effective program is one that is carefully followed. It is best to confirm that the samples are being obtained properly and to adjust the sampling frequency as needed based on recommendations by the analyst.

\section{Sampling - When, Where and How}

One of the most important parts of an oil analysis program is sampling. Obtaining a representative sample of the oil is of utmost importance, as unnecessary maintenance may be recommended based on a "bad" sample, and degradation of the equipment and oil may be missed if the sample is not representative. 


\section{A. When to Sample}

Sampling can be performed during the monthly or quarterly diesel surveillance tests as this is the most convenient time. It is best to take a lube oil sample when the equipment is running at its normal operating temperature. When that is not possible, drawing the sample within 30 minutes after the equipment is shutdown may be acceptable. Wear particles tend to settle after only a short period of time, therefore the longer the wait the more unrepresentative the sample tends to be.

\section{B. Sample Points}

For diesel engines the best location to sample is a sampling valve or petcock installed prior to the oil filter. ${ }^{14}$ Often times this is not feasible, so the oil dipstick tube or other oil filler tube may be used. Avoid areas where wear particles and contaminants settle out such as oil pan drains, heat exchanger drains and filter bypass lines. The oil pan drain connection would not be desirable for that reason.

\section{Taking the Sample}

There are two ways to sample: obtain a pressurized sample from a sampling valve or siphon the oil from the sump. When siphoning, a vacuum pump is used to draw fluid into the sample container or a bellows container draws fluid into the container when compressed and released. Siphoning may also be accomplished using a diptube. Draining is not recommended for reasons already stated, however if no other method is possible, then drain enough fluid from the drain valve to ensure that any contaminants are flushed away before inserting the sample container in the stream of oil. The above mentioned vacuum pump and associated sample bottle are Navy stock items and can be found under the following numbers:

$$
\begin{array}{lll}
\text { Pump, Oil Sampling } & \text { NSN 4930-01-119-4030 } & \text { (Quantity 1) } \\
\text { Bottle, Spectrometric \& Physical Test } & \text { NSN 8125-01-082-9697 } & \text { (Quantity 120) }
\end{array}
$$

\section{The Sample Process}

A. Draw the sample (approximately $100 \mathrm{cc}$ ) from the engine lube oil system as described above, preferably during or just after an engine run.

B. Provide information to the analysis lab: engine manufacturer and model, lube oil system capacity, hours on the engine since last overhaul, hours on the oil, API grade and manufacturer of the oil, amount of oil added as makeup, and any additional comments such as recent problems or maintenance. All of this information is vital to the evaluator of the lube oil analysis results. Recommendations are made based on the results of the test in conjunction with the information provided. It is difficult to make accurate recommendations without all of this pertinent information.

C. Package and ship the sample to the laboratory that provide the analysis.

D. Receive the report from the lab. This may occur in one of several ways: a hard copy through the mail or facsimile, download of data to an onsite computer via modem, or updates may be provided on a disk for computer storage and retrieval. 
E. Notify the lab of any inconsistency in what they recommended versus what was found during the corrective maintenance. Also alert them of the actions taken based on the recommendations. Abnormal results should trigger a re-sample to verify engine and lubricant condition. The responsibility to interpret the report and make recommendations rests upon the system engineer, maintenance engineer or technician having custody of the engine. The laboratory can only provide recommendations based on the laboratory results and typically will not be familiar with the engine's maintenance or operating history.

\section{A Basic Oil Analysis Program}

A combination of in-house and outside lab analysis can be cost effective for sites that have or intend to have a relatively large number of oil samples processed. All samples can be screened by the in-house analysis and out-of-limit or marginal results can be sent out for a full analysis by the qualified lab. The in-house program should look at basic properties such as viscosity, viscosity index, water contamination, and ferrous particulate. Some vendors have equipment that will do these tests quickly and at relatively low cost.

A. Identify and use a reputable and established lab that performs analyses based on ASTM standards.

B. Determine the method of analysis to be performed based on the equipment and its importance: spectrochemical, physical, Direct Reading and/or Analytical Ferrography.

C. Develop a sampling procedure based on industry accepted practices. Suggest JOAP or the laboratory analysis vendor literature for guidelines.

D. Train employees on proper sampling techniques, and the consequences of not sampling properly.

E. Start small. Focus the analysis on the most important pieces of equipment.

F. Establish sampling points. Identify either through procedure or on the equipment by tagging where to take the sample so consistent results may be obtained.

G. Ensure that sample forms are filled out correctly with the pertinent data required for proper identification of the oil and equipment.

H. Establish mechanism for samples to be analyzed quickly. The sooner the condition of the oil and equipment is known the better.

I. Provide a central point of contact for the lab to provide recommendations and correct deficiencies (on both sides).

J. Establish a mechanism to quickly review, confirm and publish recommendations to the maintenance organization. No one knows the condition of the equipment better than the personnel operating and maintaining it, therefore any recommendations from the analysis lab to perform corrective/intrusive maintenance on the equipment should be reviewed and confirmed by on-site personnel before action is taken.

K. Confirm that corrective actions have been performed, follow-up samples are taken, and findings are provided to the lab as feedback. 
L. Utilize oil analysis within the existing PM program, along with receipt testing, coolant and fuel analysis, vibration and thermography scanning.

\section{Estimated Cost of Oil Analysis}

It is not prudent to decrease the amount of sampling based on the cost of the individual samples. Extension of the interval between samples makes it difficult to identify potential problems because of the way wear occurs in the engine and how it is detected in the different oil analysis techniques. Small particles ( $<5$ micron) are continually being generated at a steady rate due to normal wear. As abnormal wear occurs the number of large particles ( $>5$ micron) increases in quantity and there is a subsequent increase in small particles. After a period of time the number of small particles decreases back to a normal rate while the large particles continue to be generated. Since the spectrochemical analysis is limited to small particles, an abnormal wear trend may be missed if used infrequently. Direct Reading Ferrography helps catch the increase in large particles generated prior to failure. Analytical Ferrography can be used to confirm an abnormal wear rate and to help determine whether normal or abnormal wear is occurring.

Spectrochemical and Physical Direct Reading Ferrography Analytical Ferrography
$\$ 15$ - \$20 per sample

$\$ 10$ - \$15 per sample

$\$ 50$ - $\$ 75$ per sample

Large variance depends upon whether

Photo-micrographs are provided for each sample 


\section{TYPES OF OILS}

\section{Petroleum Oil vs. Synthetic Oil}

Petroleum oil is a lubricant derived from naturally occurring mineral based stock. It has a wide application of uses and is accepted as the lubricant of choice in diesel engines.

Synthetic oils are man-made lubricants derived from one of the following classes of chemicals: synthesized hydrocarbons, organic esters, phosphate esters, poly-alkylene glycols, and silicones. $^{15}$ They are typically used when performance demands are beyond petroleum based lubricant capabilities, such as high and low temperature applications. In recent years their use has become more accepted in typical petroleum product applications due to their ability to reduce wear, sludge, corrosion and deposit formations. Synthetic oil apparently does not break down as fast in some applications and therefore lasts longer than petroleum oil. This is extremely beneficial in systems that are less likely to become contaminated with water or dirt, such as hydraulics, gearboxes, and diaphragm pumps. At this time, the typical cost of synthetic oil is about 3 times that of the petroleum oil.

Use of synthetic oils in diesels is primarily recommended when operation in extremely cold ambient temperatures (approximately $<-10 \mathrm{deg}$. F) will regularly occur. Their use is acceptable to some engine manufacturers in normal conditions as long as the synthetic oil meets the appropriate API Service categories and grades recommended for the engine. Manufacturers do recommend that the same oil change interval used for petroleum based lubricants be used for synthetic oils, therefore it is usually not cost effective to use synthetic oils unless the service demands it. This is an ever changing area of lubricant technology. Studies indicate that synthetic oils do not allow proper wear-in or break-in to occur, therefore their use is not recommended during the first several hundred hours of engine operation. Before using a synthetic based oil, contact the original equipment manufacturer for recommendations.

\section{Multi-Viscosity Oils}

Multi-viscosity oils are produced by special refining with the addition of viscosity improvers. They (VI improvers) provide for easier starting in cold weather yet allow the oil maintain desirable viscosity at elevated temperatures. Some engine manufacturers do not recommend multiviscosity oils for their diesel engines because the viscosity will vary slightly in engines subjected to wide variations in power output and speed. Also, there has been some abnormal engine part wear and high oil consumption attributed to the use of multi-viscosity oils. Shearing of the long chain polymers that exist in multi-viscosity oils can cause unexpected changes in viscosity and lead to engine failure. Typically, an engine vendor or original equipment manufacturer (OEM) will test a particular engine model with various commercially available lubricating oils. If engine wear and oil consumption data are acceptable to the vendor, the oil will be endorsed. Vendors test with multi-viscosity and synthetic oils and either publish an endorsement of the oil or make clear statements not to use those oils. The OEM should be contacted to evaluate the proper oil for each engine.

\section{Zinc-Free Oils}

Zinc additive compounds such as zinc dithiophosphate are blended into many lubricating oils, but can cause severe damage in engines with silver-coated bearings in highly loaded applications. The highly loaded bearings in question tend to wipe during operation once the silver coating is gone. Galvanic corrosion occurs between the zinc compound and silver material. Degradation will occur when the engine is not running if the circulating lube oil system provides warm oil to the 
bearings in standby. As little as $10 \mathrm{ppm}$ of zinc can be considered excessive and therefore unacceptable for use with silver bearings. Engine manufacturer's whose equipment is susceptible to this degradation suggest using a zinc-free oil. The OEM should be contacted to choose the proper oil for your engine.

\section{Engine Oil Additives}

Today's engine oils are made up of a refined base stock and a specific balance of additives to meet the API Service Classification desired performance characteristics. Use of supplemental, secondary market additives such as friction reducers, teflon derivatives, etc. can upset the balance of additives formulated into the oil. Additive drop-out can occur, causing sludge build-up and oil filter blockage. Supplemental additives are discouraged by the DOE-BPWG, engine manufacturer's, and lubricant producers. Engine damage may result from using these additives. 


\section{RECOMMENDED OIL GRADES}

Lubricating oils for engines are classified by viscosity grades. Viscosity is a measurement of the oil's resistance to flow 16 . Engine manufacturer's specify which grades of oil can be used in their engines for several reasons. Oil must be able to perform satisfactorily in varying conditions to minimize wear at high engine temperatures and to aid in successful starting at low temperatures. Oil at low temperature requires more energy to pump, longer starting cycles and larger battery capacity.

The following chart taken from SAE Standard J300 is provided as a source to check the recommended grade of oil for your operating environment. Seek additional guidance from the OEM for the equipment being serviced. ${ }^{17}$

$\begin{array}{lllll}\text { SAE } & \text { Low-Temp. } & \text { Low Temp. } & \text { Visc. @ } & \text { Visc. @ } \\ \text { Viscosity } & \text { Cranking } & \text { Pumping } & 100^{\circ} \mathrm{C} & 100^{\circ} \mathrm{C} \\ \text { Grade } & \text { Visc. Max. } & \text { Visc. Max. } & \text { Min. Max. } & \\ & \text { (centipoise) } & \text { (centipoise) } & \text { (centistokes) } & \text { (centistokes) }\end{array}$

$\begin{array}{lccll}\text { OW } & 3250 @-30^{\circ} \mathrm{C} & 30,000 @-35^{\circ} \mathrm{C} 3.8 & & \\ 5 W & 3500 @-25^{\circ} \mathrm{C} & 30,000 @-30^{\circ} \mathrm{C} 3.8 & & \\ 10 W & 3500 @-20^{\circ} \mathrm{C} & 30,000 @-25^{\circ} \mathrm{C} 4.1 & \\ 15 W & 3500 @-15^{\circ} \mathrm{C} & 30,000 @-20^{\circ} \mathrm{C} 5.6 & & \\ 20 W & 4500 @-15^{\circ} \mathrm{C} & 30,000 @-15^{\circ} \mathrm{C} 5.6 & & \\ 25 W & 6000 @-5^{\circ} \mathrm{C} & 30,000 @-10^{\circ} \mathrm{C} 9.3 & & \\ 20 & - & - & 5.6 & <9.3 \\ 30 & - & - & 9.3 & <12.5 \\ 40 & - & - & 12.5 & <16.3 \\ 50 & - & - & 16.3 & <21.9 \\ 60 & - & - & 21.9 & <26.1\end{array}$

Oil grades are broken down three ways: those without a "W" designation, those with a "W" designation, and multi-viscosity oils. The " $W$ " designation indicates that the oil has satisfied the low temperature cranking and pumping viscosity requirements as well as the $100 \mathrm{deg}$. $C$ viscosity requirements for the grade. The grades without a " $W$ " designation are only required to meet the $100 \mathrm{deg}$. C minimum viscosity requirements for that grade. Multi-viscosity oils meet the low temperature cranking and pumping viscosity requirements for one of the "W" grades, but also meets the $100 \mathrm{deg}$. C viscosity requirements of a "non-W" grade oil. This means a SAE 10W-30 oil can be operated over a wider range of operating conditions when compared with the single grade oil SAE 10W or SAE 30 .

Multi-viscosity oils are now recommended for two and four-cycle especially where improved startability is required at low temperatures. Improved fuel consumption, better oil consumption control, and better film lubrication at high temperatures are some of the benefits of using multiviscosity oils. Always follow the original equipment manufacturer's guidelines for viscosity grade and API Classification. 


\section{DISPOSITION OF USED OILS}

Used oil may be handled by Recycling, Re-refining, and disposal. The first of these are the most environmentally attractive choices.

Recycling is an application where the used oil is filtered to remove contaminants and then used again as a lubricant usually in less. severe operating conditions, such as a chain lubricant. Only one process is generally recognized as being acceptable for diesel engine oil re-refining. This process is one in which the oil is treated as a crude oil, subjecting it to the same refining process used for geological crude. The process involves dehydration, vacuum distillation, and hydrogenation.

Used lubricating oil may be provided as a fuel source for a co-generation or an incinerator facility. 


\section{FLUSHING OIL SYSTEMS}

Flushing is often recommended for larger engines when a major parts failure has occurred, the oil contains an excessive amount of water or antifreeze deposits, or whenever the engine is being removed from storage. Ancillary equipment such as filter housings, heat exchangers, and external piping should be cleaned separately to prevent particulate from dropping into low velocity areas.

Most engines can be flushed with the oil grade that would normally be used in the engine. Heating the oil helps break sludge deposits carrying particulate with it through filter bags. Water in the oil system can be flushed with oil, however kerosene sprays may be needed to break-up the oil/water emulsion. If ethylene glycol has been introduced into the oil system, sludge and tar-like build-up can be found. Therefore, a material other than oil is necessary to adequately flush the system. Butyl cellosolve or ethylene glycol monobutyl ether mixed with lubricating oil is recommended to remove the deposits. The OEM should be consulted when performing a flush using these materials since the ratio of butyl cellosolve and oil varies from manufacturer to manufacturer. Contact the DOE BPWG for assistance in obtaining more detailed information on flushing engine lube oil systems. 


\section{PRESERVATIVE OILS}

Preservative oils would be used to replace normal engine fluids if the engine were going to be inactivated for 6 months or more. These preservative oils prevent corrosion better than the normal service fluids by leaving a thin, non-drying, protective film on the engine internals. Several grades exist within Military Standards MIL-C-16173 and MIL-L-21260 to accommodate the length of time the engine will be inactivated. Generally speaking, the longer the intended inactive period, the more tenacious the grade of preservative oil required for proper protection. A thorough overview of preservative oil selection, application and removal can be found in NAVSEA Handbook S9086-HB-STM-000/CH-233. ${ }^{19}$ If sufficient care is taken to secure all openings to the atmosphere when preserving engines, the entrance of dirt, foreign material, and moisture can be prevented. Blank flanges, dark thick plastic bags and specialty tapes that can withstand repeated temperature fluctuations and weather conditions should be used. A corrosion resistant metal tag should be applied to the equipment stating that the engine has been preserved and listing, date, point of contact, the procedure/method/preservatives used and those steps needed for safe return to service. 
IX. REFERENCES

1. U.S. Navy Diesel Engine Inspector Handbook, Part II, Technical Information, S9233-CJ-HBK-020, Chapter 16, p. 16-1, published by direction of Commander, Naval Sea Systems Command

2. Standard Practices for Low and Medium Speed Stationary Diesel and Gas Engines, $6^{\text {th }}$ Edition, p. 94, Diesel Engine Manufacturers Association (DEMA), 1972

3. P.J. Louzecky, Private Correspondence to DOE BPWG Diesel Subcommittee Chairman, dated June 22, 1993. Not a public document (npd)

4. NAVEDTRA 10541-C2, Engineman 3\&2

5. Qualitative Study of General Motors 278A vertical mounted porous chrome plated cylinder liners coated with SAE 30 Wt, REG/RHM - SRS, April 1994 (npd)

6. Karl W. Stinson ME, Diesel Engineering Handbook, 12th edition,

7. Bulletin IMC-200, Section II, p. 19, Kim-Hotstart Mfg.

8. Technician's Guide, Lube Oil Analysis Primer for Diesel Engines, Characteristics/Analysis, Detroit Diesel Allison, 1984

9. Lubricating Oil for EMD Engines - Marine, Power, and Drilling Rig, Maintenance Instruction 1760, Rev. G, Electro-Motive Division, General Motors Corporation

10. Joint Oil Analysis Program (JOAP) Manual, Navair 17-15-50, published by direction of Commander, Naval Air Systems Command under the authority of the JOAP Regulation, September 1, 1990

11. Maintenance and Construction Procedure, Testing Used Lubricating Oils, PL24, E.I. duPont de Nemours \& Co., May 1987 (npd)

12. Oil and Your Engine, Caterpillar Inc., 1990

13. Instruction Manual, Maintenance Through Analysis, Form AIIM, p. 7, Analysts Inc., 1988

14. Basics of Oil Analysis, Form 4015, p. 4, Analysts Inc., 1992

15. Ron Holzhauer, "Guide to Synthetic Lubricants", Plant Engineering, Volume 48, No. 16, p. 67, Cahners Publishing Co., December 1994

16. Cummins Engine Oil Recommendations, Cummins Operation and Maintenance Construction and Industrial Bulletin 3810340, p. 3-2, Cummins Engine Company, Inc.

17. SAE J300 FEB91, Engine Oil Viscosity Classification, Society of Automotive Engineers

18. Detroit Diesel Engine Requirements - Lubricating Oil, Fuel and Filters, 7SE270 9505, p. 7, Detroit Diesel Corporation

19. Naval Ships' Technical Manual, Diesel Engines, S9086-HB-STM-000/Chapter 233, published by direction of Commander, Naval Sea Systems Command, 